\title{
THE EUROPEAN MOBILE DATA SERVICE DILEMMA
}

\author{
An empirical analysis on the barriers of implementing mobile \\ data services
}

\author{
Martin Steinert and Stephanie Teufel \\ iimt (international institute of management in telecommunications), \\ University of Fribourg / Switzerland, \\ Boulevard de Pérolles 90, CH-1700 Fribourg, Switzerland. www.iimt.ch
}

\begin{abstract}
Based on a survey of 294 Swiss businesses, the study describes the desolate state of the art of mobile data services in relation to forecasts and different investment strategies employed by companies. Additionally, an investment confidence indicator is presented. In a next step, using a contingency a11alysis. it may be concluded that in Switzerland, which may act as an indictor country for Western Europe, there exists a (set of) common factor(s) of non-technical nature, which detain(s) companies from adopting mobile data services. A probing insight into the reasons why cornpanies refrait from implementing mobile data services is given afterwards. Lastly, a concluding summary as well as a reference to a continuative research project is provided.
\end{abstract}

Keywords: empiric survey, Western Europe, mobile data services, barriers of implementations, contingency analysis.

\section{THE PENDING SUCCESS OF MOBILE DATA SERVICES IN EUROPE}

After the transformation of IT services by the global success of the internet and its web based services, the eyes of the ICT community have been focusing on equivalent developments in the mobile sectur. Having overtaken the internet in terms of penetration the mobile hand sets in their various embodiments are already deeply integrated in the everyday private and business 
life. In fact, GSM, the European second generation mobile communication system and its extensions are considered as "the fastest growing communication technology of all times" (GSM Association, 2005) with a global market share of roughly $75 \%$ out of a total subscriber base of $\sim 1.700$ million in terms of users in December 2004. (GSM Association, 2004) (EMC (European Mobile Communication) Database, 2005) Although this success is undisputed, the identification of mobile data services as the future sources of revenue and earnings growth has grossly misfired. In 2001, the idea was that mobile data services would given "Europe a crucial head start in the race toward development of a new era of wireless services that [would] make wireless Information Society a reality" (GSM Association - GSM Europe, 2001, p. 2). The EITO (European Information Technology Observatory) leaned even further out of the window. Besides forecasting an explosive growth in mobile E-commerce users, the EITO Report 2001 predicted, an European market Annual Revenue per User (ARPU) increase for mobile E-commerce from "less than Euro 200 in 2000 to about Euro 500 in 2005" (EITO (European Information and Technology Observatory), 2001, p. 276). One has to note that the forecasted 500 EUR comprises mobile data services only. Even in 2003, after the ICT bubble had defiantly burst, EITO went even further predicting a CAGR (Compound Annual Growth Rate) on mobile Commerce in Western Europe between 2002 and 2006 of $140 \%$ - annually notabene. (EITO (European Information and Technology Observatory), 2003, p. 40)

However, as anecdotal evidence strongly suggests, this bright picture of the future of mobile data service was too rosy by far. Nokia's Mikko J. Salminen realized in 2003 that "... we were sailing in tornado on the top of mobile hype curve" (Anonymous, 2003); he recognized a diffusion gap of the mobile future of around 5 years. Already in 2002, Lars Boman, the head of Ericsson Mobile Internet, had to admit: "The reality is that the introduction of new technology in networks and mobile devices has taken a longer time than anticipated. In addition it has taken a longer time for operators to turn the technology into compelling end-user services" (Timo Poropudas, 2002). The introduction of $2.5 \mathrm{G}$ technology such as HSCSD and GPRS but also EDGE and the rollout of UTRAN-FDD networks, often dearly paid for, has been continuously delayed. In private, executives admit that the cost of $3 \mathrm{G}$ networks have simply been written off - there is no intention left for $3 \mathrm{G}$ business case to break even, let alone to make a profit.

Following up on the pending success of mobile data services in Europe, this study explores the described dilemma empirically. 


\section{OBJECT, INTENTION AND COMPOSITION OF THE PAPER}

It is the aim of this paper to firstly pinpoint the state of the art of European mobile data services and to secondly explore the question why businesses refrain from introducing and using mobile data services.

The mobile data services of interest in this project are packed switched services running over an air interface on the physical layer and using either next generation mobile communication networks $(2.5 \mathrm{G}$ and $3 \mathrm{G})$ or wireless internet (WLAN) networks as bearer service. Following Porter's argumentation (Porter, 2001), services are divided into two types: one concentrating on operational effectiveness and one on creating value directly for the customer. Depending on the distribution, different strategic approaches may be derived.

The observed business theatre is Switzerland, which may act as an indicator country for the Western European economies because of its well established ICT market and its proven test market capability.

A brief introduction of the methodology and the underlying data of the study (see 3.1) precedes the empirical observation on the 294 Swiss businesses in the sample. The intention of the study is to firstly provide a descriptive view on the current adoption of mobile data services as well as future concrete investment plans of such services (see 3.2). The results are to be compared with the $140 \%$ CAGR forecast of EITO in 2003. Next, a pattern of companies embracing or refraining from mobile data services will to be established via a cross table contingency analysis (see 3.3). The resulting picture is further elaborated by an explorative study of qualitative nature (see 3.4). Finally, an outlook is given, putting the results into an international perspective and recommending further research.

\section{THE SURVEY: FUTURE OF MOBILE DATA SERVICES}

This chapter presents the result of an empirical survey of Swiss Businesses on their deployment of Mobile Data Service. After giving some general information about the underlying sample and methodology the descriptive results will be presented: current usage of Mobile services and planned investment in Mobile services including a investment confidence indicator. Next the results will be check for statistical associations followed by an explorative empirical analysis on possible barriers to implement Mobile services. 


\subsection{Basic Information on the Survey}

The data presented in this paper originates from the telecom guide Switzerland, an annual survey of Swiss Businesses by the international institute of management in telecommunications (iimt) of the University of Fribourg / Switzerland. The telecom guide Switzerland, published annually since 1998 targets the CTOs (Chief Technology Officers) of Swiss businesses. It aims to continuously track the subjective satisfaction of businesses with their ICT provider in terms of fix line services, mobile services and ISP services. "Future of Mobile Data Services", the add-on to the 2003 questionnaire, out of which the results are being presented in this paper, starts with a brief introduction including a definition of the services and mobile technologies in question. The next three question sets (nominal values) had to be answered by the respondents. An open, qualitative question concludes the questionnaire's mobile service special.

Due to the B2B nature of the survey, the universe of interest is composed of Swiss businesses. Although, in 2001, there have been 317.739 business registered, which form the theoretical universe; of theses, only about 52.000 qualify as active in the B2B market. (Bundesamt für Statistik (BFS), 2002, p. 4) (Schlienger et al., 2003, p. 7) They have been selected as basic population of the study. Those 52.000 companies are enclosed in the database from Kompass. (Anonymous, 2005). Out of the data sets in the database, 32.755 qualified for further use (the other data sets were incomplete in terms of sector affiliation and/or company size. Out of the remaining data sets, a random sample of 5.000 companies has been selected. They were contacted in autumn 2003 via mail. An additional 5.000 companies have been addressed by Euroforum, the sponsor and media partner of the telecom guide Schweiz 2003. (Euroforum, 2005).

The special on mobile data services has been answered by 294 companies which equals a return quote of $2.87 \%$. $(n=294)$ Of theses companies, $22 \%$ chose to answer online the other returned the filled out questionnaire by snail mail or fax. For a comparison in terms of internet proficiency of Swiss businesses, the OECD has published the following numbers for 2002: PCs/Workstations/Terminals diffusion $96.2 \%$, E-mail usage $92.7 \%$ and internet usage $92.1 \%$. Nevertheless, most businesses chose to traditionally answer the physical questionnaire. (OECD - Organisation for Economic Cooperation and Development, 2004, p. 9)

Concerning the sample allocation in terms of cultural regions, the distribution of languages in the sample was as follows: German speaking $84 \%$ and French speaking $16 \%$. This compares to the language distribution in Switzerland: German speaking $64 \%$, French speaking $20 \%$, Italian speaking $6 \%$ Romantsch speaking $1 \%$ and $9 \%$ other languages. It may be noted, that 
the sample represents the general Swiss allocation between the German and the French speaking population - though with a slight prevalence of German. The excess weight, however, is justifiable on the basis of the higher share of economic activities of the German speaking cantons in Switzerland.

In terms of branch affiliation and company sizes, the sample was categorized based on the Swiss Federal Statistical Office official classification in categories: Nomenclature Générale des Activités Economiques (NOGA), which equals the general classification for economic activities in the European Community (NACE). The production and trading sector accounts for $58 \%$ in Switzerland (excluding agriculture) compared to the $34 \%$ in the sample. (Schlienger et al., 2003, p. 14) The service sector (excluding agriculture) accounts for $42 \%$ in Switzerland, compared to $51 \%$ in the sample. (Schlienger et al., 2003, p. 14) It can be seen that, in contrast to the actual Swiss statistics, companies active in the service sector have a higher share in the sample. Concerning the sample distribution on sizes, small and medium companies are defined according to the Swiss federal statistics as having less than 250 employees. In the sample, big companies are, with $51 \%$, heavily overrepresented. SMEs' comprise $99.7 \%$ of the legal Swiss business entities and employ $67 \%$ of the national workforce.

Methodologically, the survey has been constructed as a mail survey although is has also been possible for respondents to answer the questionnaire online. For the mobile service special two types of services have been differentiated: (Schlienger et al., 2003, p. 63-64)

Mobile services, which improve operational effectiveness (Type I). Theses services aim to advance the company's production process, ultimately, by reducing the costs inside the value chain. Any mobile service reducing the time or the costs to produce a certain physical output or intangible service falls into this category. Type I services improve the effectiveness of current activities.

Mobile services, which interact directly with outside customers (Type II). Services of this type may take the form of an entirely new service, or a supplementary service to create value-add to existing products and services. Basically all company mobile services, which generate a new, direct contact to customers fall into this category. Type II services consequently approach new customers in a new way, or known clients via a new or partial new service.

Secondly, the mobile services were differentiated via their base technology: (Schlienger et al., 2003, p. 64)

- GSM (SMS) (Circuit Switched Mobile Telephony Data Services)

- UMTS/GPRS (Packet Oriented Mobile Telephony Data Services) 
- WLAN (Wireless Local Area Network based on IEEE 802.11)

- Bluetooth (Short-range radio signal - wireless networking for devices)

- GPS (Satellite based Location Information)

The nomenclature has been kept simple in order to increase the survey return. The questions asked aimed for the current usage of mobile services and the planned investments in mobile services; its results will be presented next.

\subsection{Descriptive Results}

The descriptive result of the study will be presented next. In the first part of the survey, Swiss businesses were asked to state whether they were currently using Mobile data services. An answer has been demand for each of the five technologies mentioned above. The data from the 294 businesses are converted to percentages and stated separately for services Type I (operational effectiveness) and services Type II (customer interaction).The descriptive results are presented in figure one; table one contains the according values in percent.

The data for Services Type I, which increase the internal operative effectiveness, suggests that only about $20-25 \%$ of Swiss businesses are using some kind of Mobile Date Service to decrease their internal costs. The obvious exceptions are GSM based services which are used by up to $60 \%$ of the businesses. A less fortunate picture presents itself when the same question is asked for services Type II which create direct customer interactions. It is obvious, that Mobile services Type II, i.e. services which create a new or improve an existing contact with a customer, are much less en vogie. GSM based services are still fairly in use with up to $40 \%$ of the businesses but services based on other technologies are only deployed in $4-13 \%$ of the questioned companies. More intriguingly, Type II services only are deployed by less than $3 \%$ of the companies (GSM is the exception with $5.8 \%$ ).

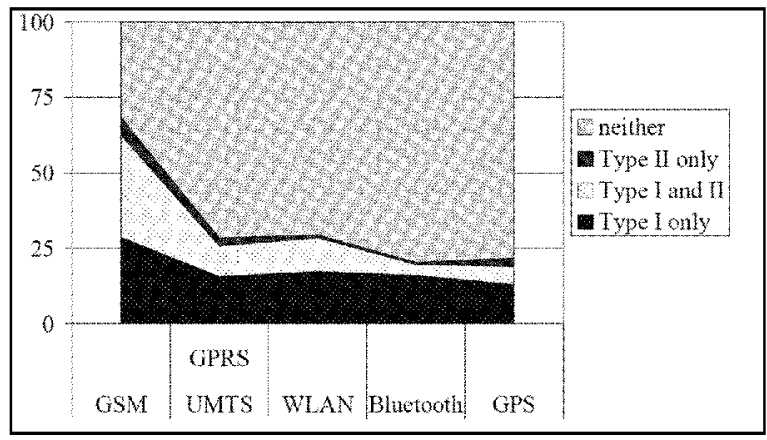

Figure 1. Current Usage of Mobile Services in percent 
Table 1. Current Usage of Mobile Services in percent $(\mathrm{n}=294)$

\begin{tabular}{|c|c|c|c|c|c|}
\hline & GSM & $\begin{array}{l}\text { UMTS } \\
\text { GPRS }\end{array}$ & WLAN & Bluetooth & GPS \\
\hline Type I only & 28.6 & 15.6 & 17.3 & 16.0 & 12.9 \\
\hline Type I and II & 34.0 & 10.2 & 11.2 & 3.7 & 6.1 \\
\hline Type II only & 5.8 & 2.7 & 1.0 & 0.7 & 2.7 \\
\hline Neither & 31.6 & 71.4 & 70.4 & 79.6 & 78.2 \\
\hline
\end{tabular}

As a first result it must be noted that about a quarter of all companies have introduced some kind of mobile service. Most of these services target internal processes, i.e. cost cutting or profit maximization. Services which may create new communication and distribution channels to the customers (or improve the existing ones), i.e. services which may increase future revenue or Type II service are deployed only by a fraction of companies, which have opted for services of Type I. This result suggests that the deployment of mobile services originates of the internal resources strategy of companies, rather than their market development strategy. Before questioning the results more closely, the investment mood in mobile services will be presented.

Businesses were asked whether or not they intent to further invest in Mobile services during the next fiscal year. This way, the survey intents to obtain time-series relevant information, without having to be conducted more than once. Instead or solemnly stating one point in time, a more robust trend can be elaborated from the data. Parallel to the last figure and table, the results are presented in figure two and table two.

Concerning future investments, the results allude to a more uncomfortable investment climate. Further investments in WLAN based services are supported by only around $30 \%$ of the companies. For all other services the rate decreases to between $15 \%$ and $20 \%$. When comparing the resuits with figure four, it is apparent that investments are actually slowing down in comparison to services in use. Still, Type I services seem to be favored over Type II services. Therefore, the near future should not lead to an increase of mobile services Type II relative to services Type I. The customer is not "yet" in the cross hairs of the companies. 


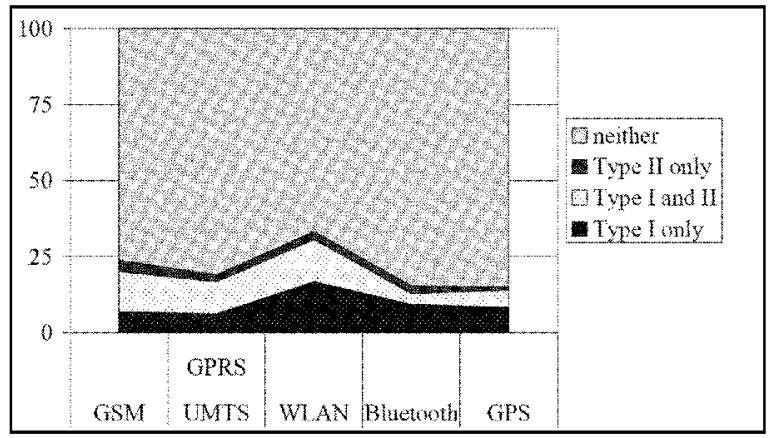

Figure 2. Companies planning Further Investments in Mobile Services in percent

Table 2. Companies planning Further Investments in Mobile Services $(\mathrm{n}=294)$

\begin{tabular}{lccccc} 
& GSM & UMTS & WLAN & Bluetooth & GPS \\
\hline Type I only & 6.8 & 6.1 & 16.7 & 9.2 & 8.2 \\
Type I and II & 13.3 & 10.5 & 13.9 & 3.7 & 5.8 \\
Type II only & 3.7 & 2.4 & 2.7 & 2.7 & 1.0 \\
neither & 76.2 & 81.0 & 66.7 & 84.7 & 85.0 \\
\hline
\end{tabular}

To get a better picture on the investment behavior and especially in the confidence in the investments, an indicator is presented next. Companies were asked, if those investment plans had been revised up- or downwards, in relation to the current fiscal year. The aim of this question is to create a trend indicator for investments in mobile services in addition to the current investment situation presented. This question turned out to be $a$ little delicate with respect to the confidentiality of internal decisions. Accordingly, only some of the 294 companies chose to answer (58-87, depending on the mobile service in question). Thus, a different way to analyze the data has been chosen. Instead of giving a percentage, which would reflect the whole sample, a trend indicator is shown, based on summing up the positive $\left(\right.$ dec $\left._{\text {pos }}\right)$ or negative $\left(\mathrm{dec}_{\text {neg }}\right)$ decisions to revise the current investment plans.

The resulting confidence indicator (con_ind) is calculated in the following way:

$$
c o n \_i n d=\frac{\sum d e c_{p o s}-\sum d e c_{n e g}}{\sum d e c_{p o s}+\sum d e c_{n e g}}
$$

con_ind $=$ confidence indicator

$\operatorname{dec}_{\text {pos }}=$ positive investment reassessment decision

$\operatorname{dec}_{\text {neg }}=$ negative investment reassessment decision 
The confidence indicator results in values, ranging from +1 , which equals unrestricted upward revision of the investments of all answering companies, and -1 , indicating that all companies have revised their investment decision downward. Table three present the results.

Table 3. Confidence Indicator $(\mathrm{n}=294)$

\begin{tabular}{llllll}
\hline & GSM & $\begin{array}{l}\text { UMTS } \\
\text { GPRS }\end{array}$ & WLAN & Bluetooth & GPS \\
\hline $\operatorname{dec}_{\text {pos }}$ & 30 & 24 & 44 & 14 & 18 \\
$\operatorname{dec}_{\text {neg }}$ & 51 & 39 & 43 & 44 & 41 \\
missing & 213 & 231 & 207 & 236 & 235 \\
\hline con_ind & -0.26 & -0.24 & 0.01 & -0.52 & -0.39 \\
\hline
\end{tabular}

The investment confidence indicator clearly points into a negative direction. The current investment mood is abating in the case of four technologies and merely neutral for WLAN. The already negative investments trend described in 2.2.2 is hence further supported. Since most companies focus on mobile services Type I, it seems that companies may develop a growing distrust in the cost-cutting abilities of mobile data services. According to the confidence indicator, only the further adoptions of WLAN seem to realize the promised benefits. A boom though is nowhere in sight.

When comparing the ambitious forecast of $140 \%$ annual growth for mobile commerce between 2002 and 2006 made by EITO (see page 2) and the results from the survey as presented in the last few sections of this papers the positive forecasts have to be seriously doubted. An extraordinary positive change in demand and business activities is needed to reach the fare stretched goal - as the investments confidence indicator implies tho igh, three digit growth is unrealistic. Basically, for a company to achieve a lasting competitive advantage, Mobile data services can have iwo directions of impact: cost cutting or product/service differentiation. (Porter, 2001) Type 1 services support a cost-leadership or price strategy. Unfortunately, advantages for this strategy, as developments in the internet show, are short lived. After a short time span, competitors are usually able to obtain the same services, thus rendering the advantage useless. The achieved higher level of competitiveness by the innovation leading company will in due time diffuse into the entire industry. Eventually, the cost-cutting technology will become a standard technology and more of a "must have" than a distinguishing factor creating a competitive advantage. Market growth for Mobile services of this Type I services are based on clearly communicated cost savings, e.g. by installing a WLAN instead of laying cable in new buildings. However, as this study shows, the momentum for increased investments in type I services 
is fading; with the exception of WLAN companies seem to think little more efficiency gains are to be expected by mobile data services. Type II services, on the other hand, are services which create new products in itself or which upgrade a product by offering a new distribution channel or by further improving existing products and services with added value. This Type II service strategy leads to a product/service differentiation for which the successful company may demand and get a price premium. After the prevailing opinion of business scholars, the successful introduction for new products or distribution channels also leads to a longer lasting competitive advantage. This contrasts to gains from a price strategy (Type I services). A differentiation strategy (Type II services) is usually more stable and enduring. Competitors have a harder time copying the advantage since the introduction of new services and the creation of new products usually take more time and investments than to simply introduce cost-cutting technology off the shelve. Instead a Type II mobile service strategy may even lead to the creation of entire new market niches, which, in time, may be able to challenge established industries due to their novel approach and superior technology. As such Amazon, Ebay and Google are probably the best current examples from the internet nexus. By creating niche markets based on technological advantage or customer satisfaction, Type II strategies tend to last and are often the first step to attack the incumbent later on from higher ground. However, in order to implement such success stories, companies need a strategic intent to discover and create the new value chain down to the customer. This intent must be sufficiently strong and determined to support investments which will not amortize in a singie fiscal period. As the presented survey shows the intention to introduce Type II mobile data service seems to be litinited to only a few companies. The disruptive evolutions needed to achieve the forecasted $140 \%$ annual growth in the industry seems to be far away. Having established this picture from the data, the question at hand is to ask why companies refrain from investing into Type II mobile services. Why has the praised mobile revolution, creating a vast amount of new application, not been launched yet? Approaching this question on the foundation of the empirical data, a contingency analysis is presented next.

\subsection{Cross Tabulation and Contingency Analysis}

In order to understand which factors are actually hindering mobile growth the empirical data base of the survey is further analyzed. The following theoretical background on cross tabulations and contingency analyses are mainly based on (Backhaus et al., 2003, p. 229-257).

Since we are dealing with nominal variables a cross tabulation and contingency analysis may be used to expose and check hidden associations and 
interrelationships. The aim is to uncover whether an association in the sample is based on coincidence or a systematic interrelationship. The data sets in question are the responses on the question on usage and on investment of mobile services. The resulting table spans a $n_{i j}(i=5$; GSM, UMTS/GPRS, WLAN, Bluetooth and GPS) ( $\mathrm{j}=4$; Type I only, Type I and II, Type II only, neither). Since there are only very few counts for Type II only, the data has been recoded for $\mathrm{j}=2$ (mobile service, no mobile service) in order to prevent insufficient cell counts which would result in meaningless results.

The contingency analysis now statistically checks the independence of the attributes combined in a cross table; in our case it compares the companies' responses concerning their mobile data service usage/investments per technology. For example the usage of GPS based services vs. the usage of Bluetooth based services. The statistical hypothesis $\mathrm{H}_{0}$ is: $\mathrm{X}$ and $\mathrm{Y}$ are independent from each other, i.e. the decision of the companies to use GPS based services is independent from the decision to use Bluetooth based mobile services. The statistical test generally used is Pearson's Chi-Square $\chi^{2}$-test. However, if the cell count is between 20 and 60 items, Yate's Continuity Correction has to be calculated; for cell counts below 20, Fisher's Exact Test is used. Cell counts below 5 produce meaningless results - there are no such events in the presented analysis. WLAN x GSM has the smallest cell count in the table with 18; Fisher's Exact Test applies.

The second important question after uncovering a dependency is to measure the strength of the interrelationship. An often used measurement is the Phi Coefticient $(\varphi)$ and Cramer's V. Since both are identical if binary variables are used $(j=2)$, the values are presented only once. $\varphi$ may result in values above 1 ; in this case literature suggests using the Contingency Coefficient. This case does not apply. Table four presenis the results of the contingency analysis on the basis of the data concerning the usage of mobile ser. vices.

Table 4. Contingency Analysis - Usage of Mobile Services ( $\mathrm{n}=294)$

\begin{tabular}{lllll}
\hline & \multicolumn{1}{c}{ UMTS GPRS } & \multicolumn{1}{c}{ WLAN } & \multicolumn{1}{c}{ Bluetooth } & \multicolumn{1}{c}{ GPS } \\
\hline \multirow{2}{*}{ GSM } & $\left..000^{* * *} 3\right)$ & $\left..009^{* * *} 3\right)$ & $\left..000^{* * *} 3\right)$ & $\left..000^{* * *} 3\right)$ \\
& $\left..268^{* * * *} 4\right)$ & $\left..153^{* * * *} 4\right)$ & $\left..236^{* * * *} 4\right)$ & $\left..252^{* * * *} 4\right)$ \\
\hline UMTS & & $\left..000^{* *} 3\right)$ & $\left..000^{* * *} 3\right)$ & $\left..000^{* *} 3\right)$ \\
GPRS & $\left..332^{* * * *} 5\right)$ & $\left..446^{* * * *} 5\right)$ & $\left..250^{* * * *} 4\right)$ \\
\hline \multirow{2}{*}{ WLAN } & & $\left..000^{* * *} 3\right)$ & $\left..428^{* *} 1\right)$ \\
& & $\left..300^{* * * *} 4\right)$ & $\left..055^{* * * *} 4\right)$ \\
\hline \multirow{2}{*}{ Bluetooth } & & & $\left..000^{* *} 3\right)$ \\
& & & $\left..244^{* * * *} 4\right)$ \\
\hline
\end{tabular}

The significance tests are labelled as follows: 
**

***

1) $>0.05$

2) $<0.05$

3) $<0.01$
Yate's Continuity Correction, Asymp. Sig. (2-sided) / cell size 20-60

Fisher's Exact Test, Exact Sig. (2-sided) / cell size 5-19

(not significant association)

(significant association)

(highly significant association)

The strength indicator Phi is labelled as follows:

$* * * *$

4) -0.3 to +0.3

5) +0.3 to +1.0

6) -1.0 to -0.3
Phi Coefficient, Value (equals Cramer's V)

(trivial dependency)

(non-trivial, positive dependency)

(non-trivial, negative dependency)

The surprising result presents highly significant associations over all technologies, with the exception of WLAN x GSM). In terms of strength, the dependencies are positive but indistinct though they exist with $\varphi$ values around +0.025 to +0.30 . To check the results a comparative contingency analysis of the same data but concerning the variables langue, company size, company branch affiliation and answer channel used has been calculated no similar dependencies are apparent.

To check further, the same analysis has been run on the data collected concerning further investments planned in mobile services. Table five presents the results.

Table 5. Contingency Analysis - Futther Investınent in Mobile Services (I)=294)

\begin{tabular}{|c|c|c|c|c|}
\hline & UMTS GPRS & WLAN & Bluetooth & GPS \\
\hline \multirow{2}{*}{ GSM } & $.001 * * 3)$ & $.000 * * 3)$ & $.057 * * * 1)$ & $.000 * * 3)$ \\
\hline & $\left..197^{* * * *} 4\right)$ & $282 * * * * 4)$ & $.117^{* * * * 4)}$ & $.280 * * * * * 4)$ \\
\hline UMTS & & $.000 * * * 3 j$ & $.000 * * * 3)$ & $\left..000^{* * 3} 3\right)$ \\
\hline GPRS & & $429 * * * * 5)$ & $227^{* * * * 4)}$ & $.355 * * * * 5)$ \\
\hline \multirow{2}{*}{ WLAN } & & & $.000 * * * 3)$ & $.002 * * 3)$ \\
\hline & & & $\left..261^{* * * * 4} 4\right)$ & $.189 * * * * 4)$ \\
\hline \multirow{2}{*}{ Bluetooth } & & & & $.023 * * * 2)$ \\
\hline & & & & $.139 * * * * 4)$ \\
\hline
\end{tabular}

The significance tests are labelled as follows:

$\begin{array}{ll}* * * & \text { Pearson's Chi-Square, Asymp. Sig. (2-sided) / cell size }>60 \\ * * * & \text { Yate's Continuity Correction, Asymp. Sig. (2-sided) / cell size 20-60 } \\ 1)>0.05 & \text { Fisher's Exact Test, Exact Sig. (2-sided) / cell size 5-19 } \\ 2)<0.05 & \text { (not significant association) } \\ 3)<0.01 & \text { (significant association) } \\ & \text { (highly significant association) }\end{array}$

The strength indicator Phi is labelled as follows: 


$\begin{array}{ll}* * * * & \text { Phi Coefficient, Value (equals Cramer's V) } \\ 4)-0.3 \text { to }+0.3 & \text { (trivial dependency) } \\ 5)+0.3 \text { to }+1.0 & \text { (non-trivial, positive dependency) } \\ 6)-1.0 \text { to }-0.3 & \text { (non-trivial, negative dependency) }\end{array}$

Again, all five technological investment decisions are significantly interdependent (with the sole exception of GSM x Bluethooth) - again the strength of the dependency is rather weak but aligned positively.

Before drawing conclusions, it must be noted though that the contingency analysis is not able to verify cause-effect relationships but correlations only. Concerning a possible bias it must be noted that the presented result originate from one single survey sample, that is from one point in time. The construct validity and reliability though can be considered as high.

Concerning the interpretation of the analysis, the following may be stated: Based on the cross tabulation and contingency analysis, the decision of the 294 surveyed Swiss companies whether to use mobile data services or not and whether to further invest in mobile data services or not, correlates across mobile data service of all five technologies, GSM, UMTS/GPRS, WLAN, Bluetooth and GPS. A (set of) common factor(s) detains companies from adopting mobile data services or support companies to adopt the same.

Concerning the mobile data services in question, the five scanned technologies are disparate on a multitude of technical attributes, e.g. concerning: frequency, bandwidth, transmission rate, range , two-way commurication capability, possible reception speed, localization capability, end device and its features, regulation, standardization, market diffusion, life-cycle, service price, target audience etc.

The conclusion may be drawn that there are no significant technologicai factors relating all five technologies. A thorough discussion of this aspect as well as an extensive argumentation can be found in (Steinert, forthcoming). Consequently, the common factor mentioned is of non-technical nature.

Summed up, the contingency analysis of the cross tabulation imply, that: "In western Europe, there exists a (set of) common factor(s) of non-technical nature, which detains companies from adopting moivile data services!" In order to approach the questions on what kind of factors may influence the companies' decision, the results of open qualitative question of the same study are presented next. 


\subsection{Explorative Results - Barriers of Implementation}

In the questionnaire, the Swiss companies were also asked in a qualitative open question to state from their perspective, which reason might hinder the implementation of mobile data services. Multiple answers up to three per questionnaire were allowed. 157 companies answered this question and gave a total of 318 reasons. Methodologically, 11 clusters of possible reasons have been nominated by the author. Afterwards, two researchers have independently put the 318 reasons into the 11 answer clusters. In case of diverging allocations, a third researcher has decided independently. The following 318 reasons present the resulting barriers of the implementation of mobile services:

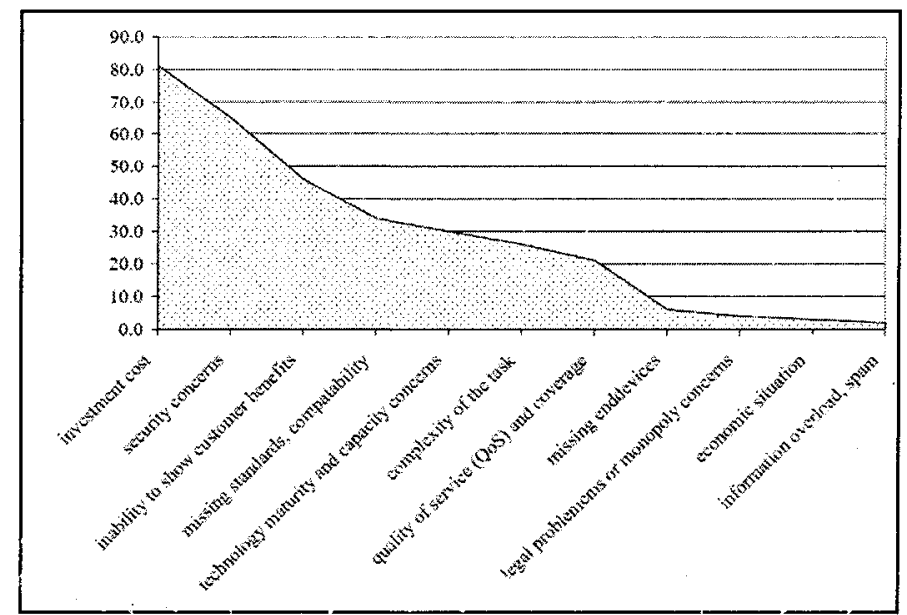

Figure 3. Barriers of Implementation of Mobile Data Services in counts

Table 6. Barriers of Implementation of Mobile Data Services

\begin{tabular}{llc}
\hline Group & Answer cluster & Counts \\
\hline 1 & investment cost & 81 \\
1 & security concerns & 65 \\
1 & inability to show customer benefits & 46 \\
2 & missing standards, compatibility & 34 \\
2 & technology maturity and capacity concerns & 30 \\
3 & complexity of the task & 26 \\
2 & quality of service (QoS) and coverage & 21 \\
2 & missing end devices & 6 \\
3 & legal problems or monopoly concerns & 4 \\
3 & economic situation & 3 \\
3 & information overload, spam & 2 \\
\hline
\end{tabular}


Interestingly, again, reasons of technical nature do not seem to be at the forefront of companies' concerns. Instead, investment costs, general (non technical) security concerns as well as the inability to identify and show customer benefits are forming the first group of reasons. This group account for $\sim 60 \%$ of the given reasons. The second group of concern which accounts for $\sim 28 \%$ of the given answers is formed by technical reasons such as missing standards and missing compatibility, technology maturity and capacity concerns, Quality of Service (QoS) and coverage concerns as well as missing end devices. The last group which accounts for the remaining $\sim 9 \%$ of the answers, includes reasons such as the complexity of the implementation task and minor reasons such as legal problems or monopoly concerns, the current economic situation or fear from information overload or spam. Of course, this last exploratory analysis is highly biased but it points in the same general direction as the contingency analysis. Summed up, in their decision to not yet adopt mobile data services, Swiss companies are not concerned with roll out problems or power supply concerns. Instead the underlying business case offered by the providers is not convincing enough to make them invest into mobile data services.

\section{CONCLUSION AND OUTLOOK}

The paper at hand is founded on a survey of 294 Swiss businesses concerning their usage and investment plans of mobile data services.

In a first step, it analysis the state of the art of mobile data services in Eurepe and compars it with the farfetched growth assumptions of e.g. EITO. Reviewing the empirical data, instead of the predicted $140 \%$ CAGR, a boom of mobile data services is nowhere in sight. Companies have so far concentrated their activities on internal services in order to cut costs. New customer relationships or the added value of existing customer relationships and hence a possibly lasting competitive advantage seem to be unattractive. For the worse, the investments confidence of companies is decreasing as well.

Based on contingency analyses, it may be assumed that across different technology platforms including GSM, UMTS/GPRS, WLAN, Bluetooth and GPS, there is a (set of) common factor(s) of non-technical nature, which detains companies from adopting mobile data services.

A first probing via an open qualitative questions results in the missing business case as a possible argument against implementing mobile data services. Providers do not seem to offer a convincing investment story (cots vs. benefits) to persuade customers to invest in mobile data services. Legal and general economic concerns do not seem to matter. 
The argument scheme of this study is the starting point of a current research project to further probe into the reason why European mobile data services fail to keep up with promises and forecasts as well as with the successful past of GSM voice services. In a comparative case analysis the macro and micro economic as well as technological and legal developments in Western Europe are compared with the two successful Asian mobile powerhouses: South Korea and Japan.

\section{References}

Anonymous. (2003). Year 2000 comes in 2006, Mobile Monday.

Anonymous. (2005). Kompassonline.Ch: Kompass.

Backhaus, K., Erichson, B., Plinke, W., \& Weiber, R. (2003). Multivariate analysemethoden (10 ed.). Berlin Heidelberg New York: Springer.

Bundesamt für Statistik (BFS). (2002). Unternehmen, arbeitsstätten, beschäftigte - die betriebszählung 2001 in kürze. Neuchâtel: Bundesamt für Statistik (BFS).

EITO (European Information and Technology Observatory). (2001). Eito report 2001.

EITO (European Information and Technology Observatory). (2003). Eito report 2003.

EMC (European Mobile Communication) Database. (2005). World cellular information service. Retrieved 09.05., 2005, from http://www.emc-database.com/ NASApp/cs/ContentServer?pagename $=$ marlin/home\&MarlinViewType=MARKT_EFFO RT\&marketingid $=20001226000 \&$ siteid $=30000000401$

Euroforum. (2005). Über euroforum. Retrieved 10.05., 2005, from http://www.euroforum.ch/about/

GSM Association - GSM Europe. (2001). Facts and figures - about gsm europe. Retrieved 09.05., 2005, from http://www.gsmworld.com/gsmeurope/about/gsm curope factsfigures pdf

GSM Association. (2604). Growth of the global digital mobile market. Retrieved 09.05., 2005, from http://Www.gsmworld.com/news/statistics/pdf/gsma stats_q4 04.pdf

GSM Association. (2005). Gsm facts and igures. Retrieved 06.05., 2005, from http://www gsmworld.com/news/statistics/index.shtml

OECD - Organisation for Economic Co-operation and Development. (2004). Ict diffusion to business: Peer review, country report: Switzerland. Retrieved 01.05., 2005, from http://www.oecd.org/dataoecd/28/12/31706392.pdf

Porter, M. E. (2001). Strategy and the internet. Harvard Business Review, 79(3), 62 (17p).

Schlienger, T., Steinert, M., \& Unterberger, C. (2003). Iimt telecom guide schweiz. Fribourg: iimt University Press.

Steinert, M. (forthcomming). A comparative cross case analysis on western european and asian mobile data services. Unversity of Fribourg / Switzerland, Fribourg.

Timo Poropudas. (2002). Slow down to reality, mobile hype is over, Mobile CommerceNet: CommerceNet Skandinavia. 